\title{
Broad, broader, broadest
}

\author{
L.X. van Nunen · S.A.W.G. Dello • L.R.C. Dekker
}

Published online: 11 April 2015

(C) The Author(s) 2015. This article is published with open access at Springerlink.com

\section{Question}

A 79-year-old woman was admitted to the emergency department because of respiratory tract infection and several near-syncopes due to intermittent third-degree AV block (Fig. 1). She had a medical history of known paroxysmal atrial fibrillation without left ventricular dysfunction, and chronic mental depression treated by oral flecainide and nortriptyline, respectively.

An underlying respiratory tract infection (C-reactive protein $150 \mathrm{mg} / \mathrm{l}$ ) with a right lower lobe infiltrate was discovered on X-ray. A temporary pacemaker lead was placed and the patient was admitted to the cardiac care unit. Flecainide and nortriptyline were stopped at admission. Over the next hours, the AV block disappeared and the following subsequent electrocardiograms were recorded (Figs. 2 and 3).

What is your diagnosis and can you explain the underlying mechanism?

Open Access This article is distributed under the terms of the Creative Commons Attribution License which permits any use, distribution, and reproduction in any medium, provided the original author(s) and the source are credited.
L.X. van Nunen $(\bowtie) \cdot$ S.A.W.G. Dello · L.R.C. Dekker Department of Cardiology, Catharina Hospital Eindhoven, Michelangelolaan 2,

5623 EJ Eindhoven, The Netherlands

e-mail: lokien.v.nunen@catharinaziekenhuis.nl 


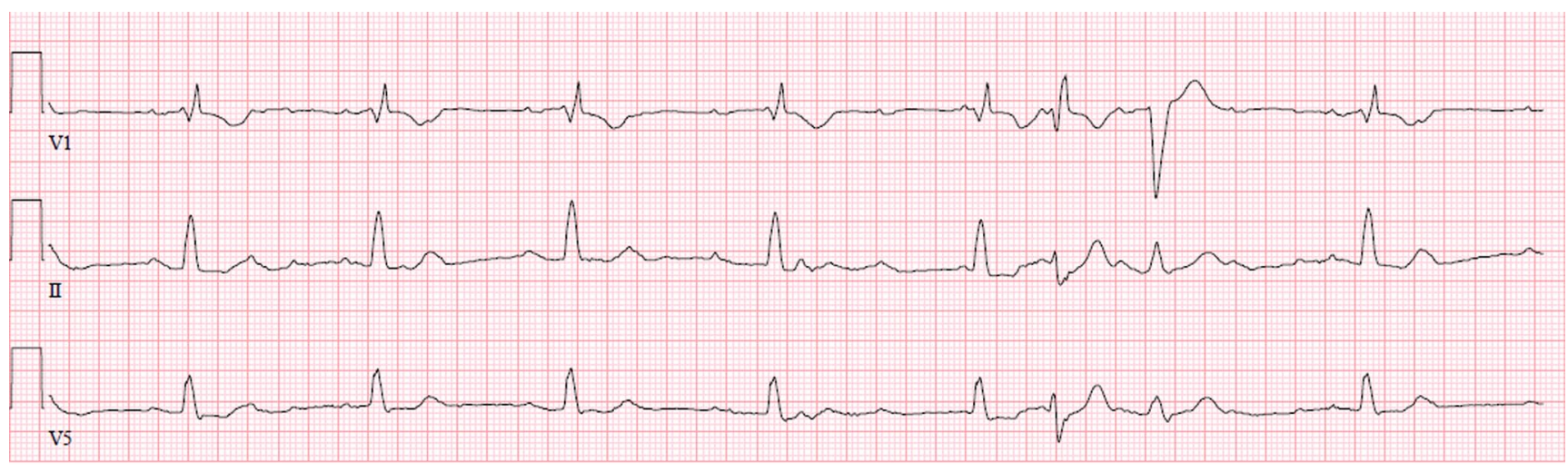

Fig. 1 ECG at presentation showing third-degree AV block

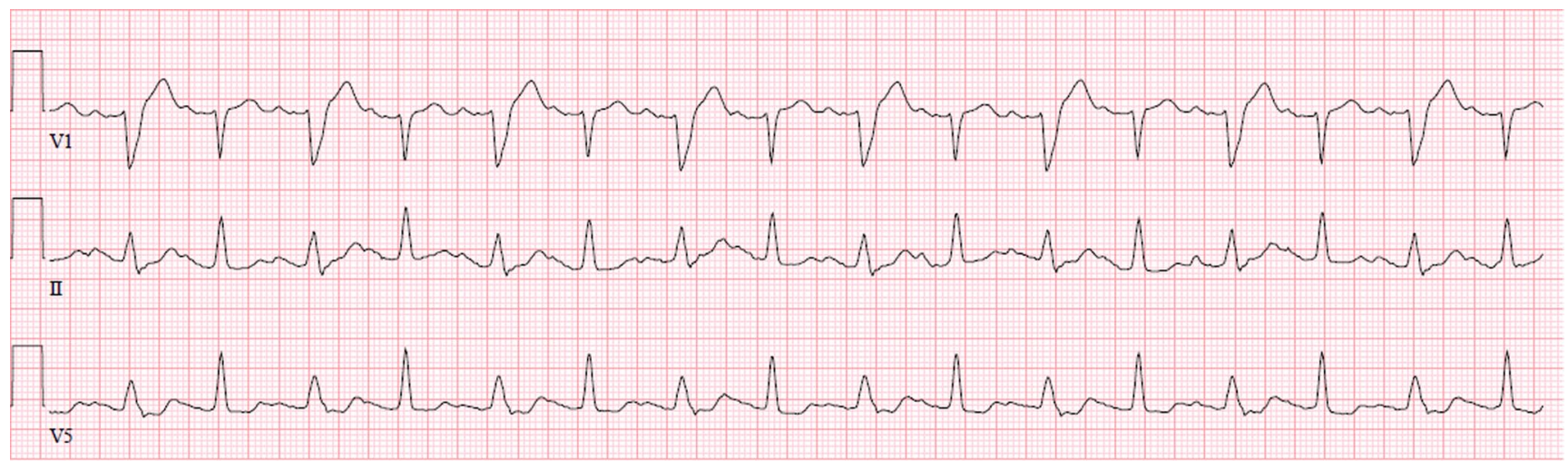

Fig. 2 ECG $2 \mathrm{~h}$ after presentation

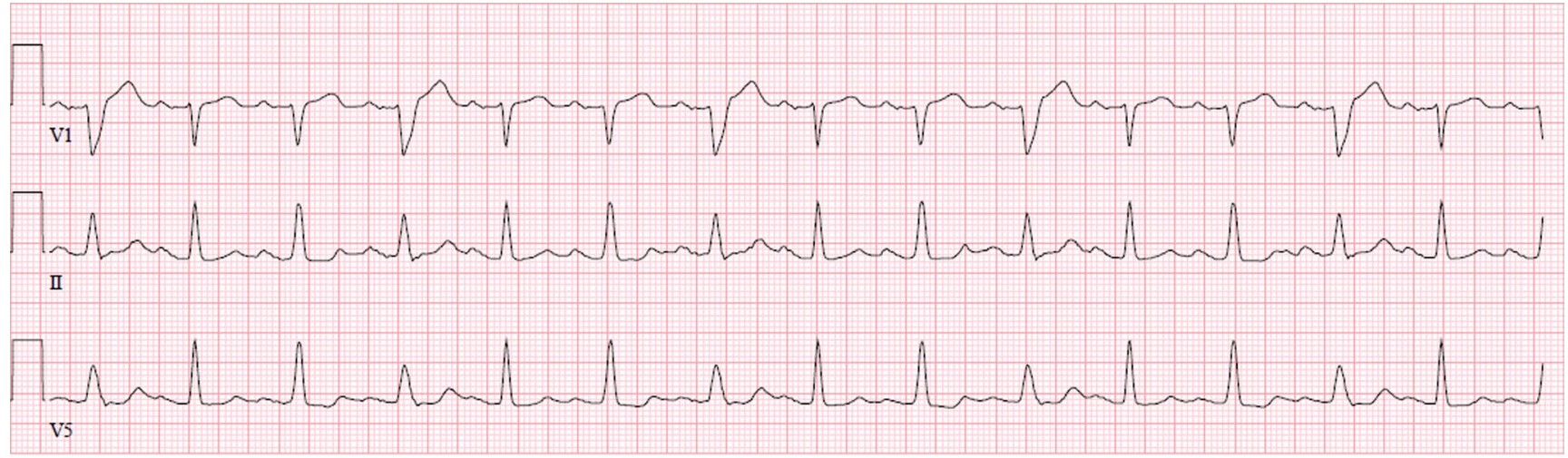

Fig. 3 ECG $3 \mathrm{~h}$ after presentation 